\title{
Evaluation of Post-operative Outcome in Patients with Trochanter Fracture of Femur in Treating with Proximal Femoral Nail and Dynamic Hip Screw
}

\author{
Debdulal Debnath ${ }^{1 *}$, S. M Jihadul Islam², Nazmul Huda ${ }^{3}$
}

${ }^{1}$ Associate Professor, Department of Orthopedic Surgery, Northern International Medical College, Dhanmondi, Dhaka

${ }^{2}$ Registrar, Department of Orthopedic Surgery, Northern Medical College \& Hospital, Dhaka, Bangladesh

${ }^{3}$ Consultant (Orthopedic), Upazila Health Complex, Savar, Dhaka

DOI: $10.36347 /$ sjams.2020.v08i10.015

| Received: 30.09.2020 | Accepted: 13.10.2020 | Published: 17.10.2020

*Corresponding author: Dr. Debdulal Debnath

Abstract

Original Research Article

Background: We have very few data regarding the socio-demographic and clinical status of patients with Trochanter Fracture of Femur. Trochanter fractures of the femur remains one of the most challenging fractures faced by orthopaedic surgeons. Fracture of the proximal part of the femur are an important cause of morbidity and mortality in all age groups, especially the elderly. Proximal femoral nail and dynamic hip screw system are two widely used methods in treating trochanter fracture of femur. The aim of this study was to evaluate post-operative findings of the patients with Trochanter Fracture of Femur in Treating with Proximal Femoral Nail and Dynamic Hip Screw. Methods: The present prospective comparative study has been done in National Institute of Traumatology and Orthopaedic Rehabilitation (NITOR), Dhaka, Bangladesh during the period from July 2015 to June 2017. During this period obeying inclusion and exclusion criteria 30 patients of unstable intertrochanteric fractures of femur were finalized as the study people. Among them 14 cases were treated with PFN and 16 with DHS. All statistical analysis of different variables was analyzed according to standard statistical method by Fisher's Exact Test and Student t-Test and done by using SSPS method in computer. Result: In this study $63.3 \%$ of the subjects were 65 or above 65 years and $10 \%$ below 50 years of age. Sixty percent $(60 \%)$ were male whereas $40 \%$ were female. House-wife comprised the main bulk (40\%) as occupation. Other occupants were service holders (13.3\%), businessman (13.3\%), farmer (10\%) and day-laborer $(3.3 \%)$. The rest $20 \%$ were involved with other informal jobs. Causes of injury revealed that $26.7 \%$ trochanter fractures were caused by RTA and $36.7 \%$ by fall from height and $36.7 \%$ by accident at home. Two-third $(66.7 \%)$ of the injuries had right-sided involvement. More than half $(53.3 \%)$ of subjects were operated within 7 days of the incident. Conclusion: In this study, the highest cases of Trochanter Fracture of Femur were found from aged people. Involvement of male patients was higher than female. Involvement of housewives was also alarming. Twothird portion of involvement of right sided fractures was also noticeable in this study.

Keywords: Socio-demographic status, Orthopedics, Trochanter fracture, Femur.

Copyright (C) 2020 The Author(s): This is an open-access article distributed under the terms of the Creative Commons Attribution 4.0 International License (CC BY-NC 4.0) which permits unrestricted use, distribution, and reproduction in any medium for non-commercial use provided the original author and source are credited.

\section{INTRODUCTION}

We have very few data regarding the sociodemographic and clinical status of patients with Trochanter Fracture of Femur. Trochanter fractures of the femur remains one of the most challenging fractures faced by orthopaedic surgeons. Fracture of the proximal part of the femur are an important cause of morbidity and mortality in all age groups, especially the elderly. Proximal femoral nail and dynamic hip screw system are two widely used methods in treating trochanter fracture of femur. Intertrochanteric fractures are defined as 'fractures involving upper end of femur through and in between both trochanters with or without extension into upper femoral shaft'. An increasing incidence of intertrochanteric fractures with advancing age is well known. The incidence of intertrochanteric fractures varies from country to country. Gulberg et al., [1] has predicted that the total no of hip fractures will reach 2.6 million by 2025 and 4.5 million by 2050. In $199026 \%$ of all hip fractures occurred in Asia whereas this figure could rise to $37 \%$ in 2025 and $45 \%$ in 2050 [2]. Intertrochanter femoral fracture have been estimated to occur in more than 200000 patients each year in United States, with reported mortality rates ranging from $15 \%$ to $20 \%$. Most intertrochanter femoral fracture occurs in patients over 70 years of age. Hip fractures (intertrochanter and femoral neck fractures) account for $30 \%$ of all hospitalized patients in the United States, 
and the estimated cost for treatment is approximately $\$$ 8 billion a year. ${ }^{3}$ We have no data like this but we are facing lot of patients of proximal femoral fracture in this hospital, NITOR. In our circumstances we think it will be more than that of above data in respect of mortality, morbidity, hospital stay and cost of treatment. The world-wide prevalence of the fracture of the proximal part of the femur is increasing as the average age of the population increases. Fracture of the proximal part of the femur are an important cause of morbidity and mortality in all age groups, especially the elderly. Operative treatment is the most cost effective approach for displaced intracapsular fractures and all extra capsular fractures. Thus the proper treatment of the fractures of the proximal part of the femur is important not only for the continued health and vitality of the population but also for the health and economy. Fractures of the proximal part of the femur occur predominantly as low energy injuries in elderly patients and as high energy injuries in younger patients. The high prevalence of the fractures in elderly is related to numerous factors including osteoporosis, mal-nutrition, decrease physical activities, impaired vision, neurological impairment, poor balance, altered reflex and muscular weakness. Fractures of the proximal part of the femur in elderly patients are generally the result of a single fall and are more common in women than in men. Patients who have inter trochanteric fractures are as a group slightly older and have higher rates of morbidity and mortality compared with patients who have fracture of the femoral neck [4]. There were an estimated 1.66 million hip fractures worldwide in 1990. According to the epidemiologic projections, this worldwide annual number will rise to 6.26 million by the year 2050.This rise will be in great part due to huge increase in the elderly population of the world [5]. The incidence rate of hip fractures vary considerably from population to population and race to race but increase exponentially with age in every group. Highest incidence have been described in whites in northern Europe north America [5]. The lifetime risk of hip fracture is about $16 \%-18 \%$ in white women and $5 \%$ $6 \%$ white men. At the age of 80 years every fifth women and at the age of 90 years almost every second woman has suffered a hip fracture. Since populations are aging worldwide, the mean age of hip fracture are increasing rapidly too. This change likely to cause increasing problems in the treatment and rehabilitation of the patients. In 1990, $72 \%$ of the hip fractures worldwide occurred in women. All over the world the hip fracture incidence are about two times higher in women than in men. Women over representation have been explained by women's lower bony mass and density higher frequency of falling. Epidemiologic studies show that trochanteric fractures are an increasing problems since compared with cervical fractures their relative number increases progressively with age in after the age of 60 years and since their incidence has been shown to increase in both sexes and all age groups during the recent decades. This may have direct public health implication since mortality, morbidity cost caused by trochanter fractures are higher than those of cervical fractures. Reduced bone density by age and over recent decades has been the most frequently mentioned reason for the increased of the trochanter fractures. ${ }^{5}$ Hip fractures represents one of the most important causes of morbidity and mortality among the elderly. Hip fractures are also major problems for the economics of the modern medical care [5]. The incidence of pertrochantric fractures have increased significantly during recent decades and this tendency will continue in the near future due to rising age of the population. The goal of the treatment of this fractures is stable fixation which allows early mobilization of the patient. In order to achieve this objective, several intramedullary nail have been developed. These nails may challenge the previous role of the compression screw as the standard method of fixation. Less data are available about an alternative, the proximal femoral nail (PFN), since most previous studies are retrospective and lack of control group. Moreover the main focus in previous controlled studies has been aimed at techniques and clinical results or the rehabilitation of the patients in general. We do not know if there is a difference in the post-operative recovery of walking or where the patients' lives depending upon which implant is used [6]. The main design differences between the PFN and other such devices are the introduction of an anti-rotation $6.5 \mathrm{~mm}$ neck screw; fluting of the nail tip which is said to decrease stress and finally the positioning of the distal locking screws more proximal than in some other devices hence avoiding abrupt changes in stiffness of the construct. In this series we have not seen the high incidence of peri-operative femoral fractures previously reported with the use of other similar devices [7].

\section{OBJECTIVES}

The general objective of this study was to evaluate post-operative findings of the patients with Trochanter Fracture of Femur in Treating with Proximal Femoral Nail and Dynamic Hip Screw

\section{Methodology \& Materials}

This was a prospective study which was conducted in National Institute of Traumatology and Orthopaedic Rehabilitation (NITOR), Dhaka, Bangladesh during the period from July 2015 to June 2017. During this period of study following inclusion and exclusion criteria 30 patients of unstable intertrochanteric fractures of femur were selected finally as the study people. Among them 14 cases were treated with PFN and 16 with DHS. The operation was done after selecting the cases on the basis of history, clinical and radiological findings. All the operations were performed under spinal anaesthesia. Portable XRay machine or $\mathrm{C}$-arm were used to take preoperative and post-operative radiographs. A minimum follow up 18 weeks were provided, the maximum duration of 
follow up of 12 months. According to the inclusion criteria patients of both sex, with proper occupation and socioeconomic status, patients with unstable trochanter fracture of femur of any duration were included in the study. On the other hand, according to the exclusion criteria patients who could not be followed for a period of at least 12 weeks, who could not bear the cost of PFN or DHS, patients with pathological fractures or with a source of infection in the body and patients unfit for anesthesia and major surgical inter venison were excluded from the study. Age, sex and occupation were demographic variables. On the other hand mode of trauma, side involvement, time interval between injury and operation, duration of hospital stay, fracture union and incidence of complication were the clinical variables. A pre-tested and pre-designed pro-forma containing history and examination finding of the patient and operative procedure and follow up were used to collect the data. Once data collection was completed, data were compiled and tabulated according to key variables. All statistical analysis of different variables was analyzed according to standard statistical method by Fisher's Exact Test and Student t-Test and done by using SSPS method in computer. Several parameters are involved in the analysis of outcome measurement in cases of trochanteric fracture of femur. It is difficult to evaluate the outcome uniquely in this present series due to limited period of follow up. Harris hip function evaluation scoring system is taken here. The grading were: 100-90 (Excellent); 89-80 (Good); 79-70 (Fair); <70 (Poor). In the emergency department, patients were treated by Hartman Solution, analgesics and if needed by blood. Patients were then transferred to the ward after applying surface or skeletal traction. As per need complete blood count, urine routine and microscopy, blood grouping and cross matching, blood sugar 2 hour after breakfast with corresponding urine sugar, serum creatinine, X-ray of effected thigh including hip and Knee anterior-posterior and lateral view, X-ray pelvis anterior-posterior view, X-ray chest posterior-anterior view and electrocardiogram reports were collected. In all cases, antibiotic (3rd generation cephalosporin $1 \mathrm{gm}$. IV) were given pre operatively. Surgery was performed on an average of 1-2 weeks after injury. Delay in the arrangement of operative accessories, blood, implants, lack of hospital bed, inability on the part of the patient to afford paying bed were responsible for the delay before operation. On the other hand, the goal of post-operative management and rehabilitation was to return the patients to their prefracture status at the earliest possible time. Injectable third generation Cephalosporin $1 \mathrm{gm} \mathrm{I/V}$ daily was given for 3 days. Then orally third generation Cephalosporin $200 \mathrm{mg} 12$ hourly for 7 days were given. Injectable narcotic analgesics were given 12 hourly till first postoperative day. Then injectable/suppository form of diclofenac sodium 12 hourly for 3 days and then oral form till pain subside. The patients were followed up as outdoor patients at the outpatient department. They were requested to attend outpatient department with check X-ray pelvis anterior-posterior view including both hip joints and X-ray of thigh including hip and knee joint lateral views of the affected side. The $1^{\text {st }}, 2^{\text {nd }}$, $3^{\text {rd }}, 4^{\text {th }}, 5$ th and 6 th follow-up were performed after 6 , $12,18,24,36$ and 48 weeks of operation respectively. Usually 6 weeks after operation, the patients were examined clinically and radiologically. If callus formation was seen at the fracture site, partial weight bearing with crutches was advised. After 12 weeks and in subsequent follow-up, the patients were again examined clinically and radiologically. If fracture line obliterated with callus and union was progressing, then full weight bearing was started. If not, partial weight bearing was continued till next follow-up.

\section{RESUlT}

In this study in analyzing the ages of the participants we found, $63.3 \%$ of the subjects were 65 or above 65 years and $10 \%$ below 50 years of age. The age category $50-55$ years, $55-60$ years, and $60-65$ years comprised of $13.3 \%, 6.7 \%$ and $6.7 \%$ respectively. The mean age of the subjects was $63.8 \pm 11.1$ years and the lowest and highest ages were 45 and 95 years respectively. Among the total subjects $60 \%$ were male and the rest $40 \%$ were female. Occupation of the subjects demonstrates that house-wife comprised the main bulk (40\%). Other occupants were service holders $(13.3 \%)$, businessman $(13.3 \%)$, farmer $(10 \%)$ and daylaborer $(3.3 \%)$. The rest $20 \%$ were involved with other odd jobs. Causes of injury revealed that $26.7 \%$ trochanter fractures were caused by RTA and $36.7 \%$ by fall from height and another $36.7 \%$ by accident at home. Two-third $(66.7 \%)$ of the injuries had right-sided involvement and $90 \%$ did not receive any treatment before admission in the hospital. More than half $(53.3 \%)$ of subjects were operated within 7 days of the incident.

Table-1: Age distribution of participants $(n=30)$

\begin{tabular}{|l|l|l|}
\hline Age (Years) & n & \% \\
\hline$<50$ & 3 & 10 \\
\hline $50-55$ & 4 & 13.3 \\
\hline $55-60$ & 2 & 6.7 \\
\hline $60-65$ & 2 & 6.7 \\
\hline$\geq 65$ & 19 & 63.3 \\
\hline Total & $\mathbf{3 0}$ & $\mathbf{1 0 0}$ \\
\hline
\end{tabular}

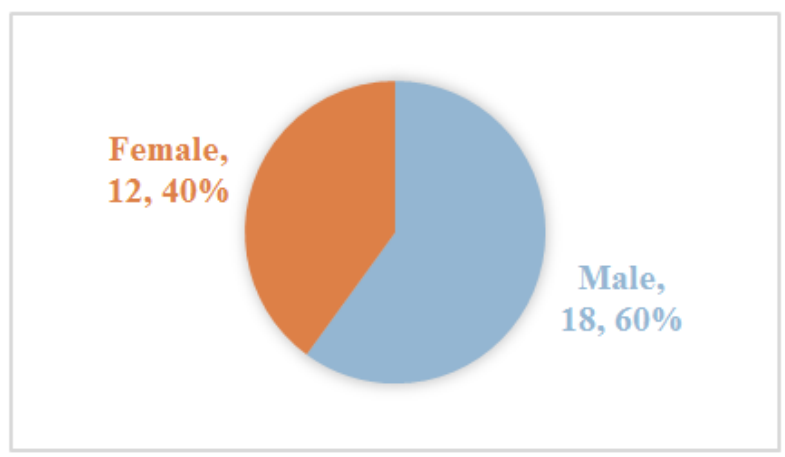

Fig-1: Gender distribution of participants $(n=30)$ 
Table-2: Distribution of occupation among participants $(\mathbf{n}=\mathbf{3 0})$

\begin{tabular}{|l|l|l|}
\hline Occupation & n & \% \\
\hline Service & 4 & 13.3 \\
\hline Business & 4 & 13.3 \\
\hline Housewife & 12 & 40 \\
\hline Farmer & 3 & 10 \\
\hline Day-laborer & 1 & 3.3 \\
\hline Other odd jobs & 6 & 20 \\
\hline
\end{tabular}

Table-3: Baseline characteristics of the injury $(n=30)$

\begin{tabular}{|l|l|l|}
\hline Characteristics & n & \% \\
\hline Causes of injury & 8 & 26.6 \\
\hline RTA & 11 & 36.7 \\
\hline Fall from height & 11 & 36.7 \\
\hline Accident at home & \multicolumn{3}{|l|}{} \\
\hline Fracture side & 20 & 66.7 \\
\hline Right & 10 & 33.3 \\
\hline Left & 2 & 6.7 \\
\hline History of previous treatment \\
\hline Conservative & 2 & 3.3 \\
\hline Indigenous & 1 & 90 \\
\hline None & 27 & \\
\hline
\end{tabular}

Table-4: Immediate postoperative outcome among participants $(\mathbf{n}=\mathbf{3 0})$

\begin{tabular}{|l|l|l|}
\hline \multirow{2}{*}{ Immediate outcome } & Groups \\
\cline { 2 - 3 } & PFN & DHS \\
\cline { 2 - 3 } & $(\mathbf{n = 1 4 )}$ & $\mathbf{( n = 1 6 )}$ \\
\hline Infection & $2(14.3)$ & $3(18.8)$ \\
\hline $\begin{array}{l}\text { Cut-out of the screw } \\
\text { loosened }\end{array}$ & $1(7.1)$ & $1(6.3)$ \\
\hline Implant failed & & \\
\hline Blood transfusion needed & $1(7.1)$ & $11(68.8)$ \\
\hline Need for further operation & 0 & $1(6.7)$ \\
\hline $\begin{array}{l}\text { Hospital stay (mean } \pm \text { SD } \\
\text { minutes) }\end{array}$ & $3.85 \pm$ & $\begin{array}{l}3.56 \pm \\
0.72\end{array}$ \\
\hline
\end{tabular}

Table-5: Findings of $3^{\text {rd }} /$ final follow up among participants $(\mathbf{n}=\mathbf{3 0})$

\begin{tabular}{|l|l|l|}
\hline \multirow{3}{*}{ Findings } & Group \\
\cline { 2 - 3 } & PFN & DHS \\
\cline { 2 - 3 } & $(\mathrm{n}=14)$ & $(\mathrm{n}=16)$ \\
\hline Infection & $1(7.1)$ & 0 \\
\hline Pain & $11(78.6)$ & $5(31.3)$ \\
\hline No pain & $3(21.4)$ & $10(62.5)$ \\
\hline Mild & 0 & $1(6.3)$ \\
\hline Moderate & \multicolumn{3}{|l}{} \\
\hline X-ray findings & \multicolumn{3}{|l}{} \\
\hline Fracture alignment intact & $13(92.9)$ & $13(81.3)$ \\
\hline Visible callus & $12(85.7)$ & $13(81.3)$ \\
\hline Screws in position & $13(92.9)$ & $13(81.3)$ \\
\hline State of union & 0 & $3(18.7)$ \\
\hline Uniting & $13(92.9)$ & $13(81.3)$ \\
\hline United & $1(7.1)$ & 0 \\
\hline Not united & $1(7.1)$ & $2(12.5)$ \\
\hline Complications &
\end{tabular}

\section{DISCUSSION}

The general objective of this study was to collect the information regarding the socio-demographic and clinical status of patients with Trochanter Fracture of Femur. The best treatment for unstable trochanteric femoral fracture remains controversial. Intramedullary devices have mechanical and biological advantages in such fractures. The PFN is designed to overcome some of difficulties encountered with earlier designs of intramedullary proximal femoral nails. Echer ML [8], treated 104 patients with DHS. Despite death and lack of follow up, the late results in 62 cases of fracture were analyzed. Three nonunion and one mal-union gave the technique of failure rate of only $6.4 \%$. There were two patients had definite infection. In my observations there were 3 cases infection in those who were treated with DHS. Parker MJ [9], studied prospectively a consecutive series of 765 patients with proximal femoral fracture to determine if the time interval between injury and surgery influence the outcome. Mortality was not significantly different but morbidity was increased by delay. I found that those patients were treated within one week, had less infection. Simmermachar RKJ [10], within one year they treated 191 proximal femoral fracture patients with the PFN. After a follow up period of at least 4 moths. Technical failure were seen in just $4.6 \%$ of the cases. The mean duration of surgery was $68.7 \mathrm{~min}$ (25-240). There was $21(13 \%)$ local complication consisting heamatoma, infection and wound healing disturbances necessitating reoperation in one case. Four months post operatively $44(40 \%)$ showed the same unrestricted walking ability. Domingo LJ [11], followed prospectively 295 patients with trochanteric fractures treated with PFN. Average age of the patients was 80 years. The average time required for consolidation was 12 weeks. Patients remained hospital for an average of 15.4 days. The most frequent complication were seroma and heamatoma of the surgical wound, which resolved satisfactorily in all cases. Superficial and deep infections also evolved favorably, once the appropriate treatment has been instituted. No breakage or failures due to implant fatigue were seen. The patient's recovery after suffering the fracture and the operation was evaluated and $71 \%$ recovered their previous walking ability. Al-Yassari [7], treated 70 patients $(17$ males and 53 females, the average age 84 years) of unstable trochanteric femoral fracture operatively using PFN. They experienced the complication of difficulty in distal locking in case of three patients, Screw cut through the femoral head in four patients. A fall at home was the commonest mode of injury. The average delay to operation from the time of injury was 3 days (range o-11days). The reoperation rate was $7.1 \%$. Herrera $\mathrm{A}$ et al., [12], a prospective randomized study was presented of 125 pertrochanteric fracture of femur treated with PFN and 125 with Gamma nail. Average age of the patients was 78.9 years. Average pre-surgical stay was 2.9 days. Length of surgical procedure average was $49 \mathrm{~min}$ for the PFN. Average requirement of blood was 1.89 units. Average 
healing time was 12 weeks. The most complications were seroma, heamatoma, which resolved satisfactorily and superficial and deep infections also evolved favorably once antibiotic was instituted. Pt remained hospitalized for an average of 14.1 days. Per operative blood loss was lower in the PFN group. There were no diaphyseal fractures when using PFN. Banan H [13], reported their experience of stabilizing 60 consecutive proximal femoral fractures with PFN. The mean was 79 years. There were 12 males and 48 females. The patients were following up for a minimum of 4 months. There was 12 deaths, two were lost to follow up. They found post operatively a good union rate at 4 months $(85 \%)$, a relative low cut out rate $(8.7 \%)$ for unstable fractures. In our study, there were 12 female and 18 male. I found postoperatively a good union rate at 18 weeks $(92.9 \%)$ in PFN group and $(81.3 \%)$ in DHS group. Boldin C [14], in a prospective study they treated 55 patients having proximal femoral fractures with PFN from 1997 to 2000 . The mean age was 73 years and 39 were female. In total 50 fractures were reduced by closed means and 5 patients reduced by open reduction were necessary. The mean duration of surgery was 68 min (22-205). A cut out of the neck screw was seen in two patients. The most widely used method for proximal femoral fracture is probably still DHS. For more distal and uncommon trochanteric fractures, the intra-operative and fracture fixation results while the PFN were better than with sliding hip screws. They consider that the PFN is a good minimally invasive implant for unstable proximal femoral fractures when close reduction is possible. The modification of the PFN and careful surgical technique should reduce the high complication rate in their study. If open reduction is needed and multiple fragment specially of the greater trochanter stabilizing plate. This minimizes excessive secondary fracture impaction and medialization of the femoral shaft. Pajarinen J [6], the treated 108 patients with a pertrochanteric femoral fracture using either by the DHS or the PFN in this prospective randomized series. Patients treated with the PFN $(n=42)$ had regained. Their preoperative walking ability significantly $(p=0.04)$ more often by the four months review than those treated with the DHS $(n=41)$. They found that the operation time was with the operation of PFN being generally more time consuming, require less blood (mean no. of transfused red blood cell unit $400 \mathrm{cc} /$ unit during hospital stay). Patients were discharged at a mean of 6 days post operatively. Restoration of walking ability was achieved more often in the patients treated with PFN (76.2\%) compared with those treated a DHS (53.7\%; p=0.04). They also observed, complications during follow up of 4 monthstwo cases of displacement. In total 19 patients did not attend final review. Their results suggest that use of a PFN in the treatment of trochanter femoral fracture may have positive effect on the speed of restoration of walking, when compared with a DHS. A total of 43 patients of unstable fracture trochanter of femur were included in the study to evaluate the comparative outcome of treatment options between Proximal Femoral Nail and Dynamic Hip Screw. The patients were purposively assigned to treatment groups - the PFN group with 18 patients and DHS with 25 patients. Of the 43 patients 2 patients died during the study period, while the 11 patients were lost to follow up. Finally the PFN group comprised of 14 patients and DHS group 16 patients. The average age was 64 years (45-95), male 18, female 12. Commonest occupation group was house wives (40\%), common cause of injury were RTA, FFH and accident at home. Two third of the patients $(66.7 \%)$ had the right sided injury, $90 \%$ of the patients did not get any treatment prior hospital admission, $53.3 \%$ patients were operated within 7 days of the incident. More than two-third $(68.8 \%)$ of the DHS group needed blood transfusion compared to only $7.1 \%$ of the PFN group. Comparison of Harries Hip score between groups shows that majority $(85.7 \%)$ of the PFN group exhibited excellent score (100-90) compared to $37.5 \%$ of the DHS group.

Limitations: It was a single centre study. So, results of this study may not be reflected in the whole country.

\section{Conclusion and Recommendations}

In this study, the highest cases of Trochanter Fracture of Femur were found from aged people. Involvement of male patients was higher than female. Involvement of housewives was also alarming. Twothird portion of involvement of right sided fractures was also noticeable in this study. But as it was a single centered study with a small sized sample. So the findings of this study may not reflect the exact scenario of the whole country. For getting more specific information we would like to recommend for conducting similar more studies in several places on larger sized sample.

\section{Funding Sources: Self}

Conflict of Interest: None declared.

\section{REFERENCES}

1. Gulberg B, Jhonell O, Kanis J. Worldwide projection for hip fractures. Osteoporos Int. 1997; 7:407e413.

2. Melton L3, Kearns AE, Atkinson EJ, Bolander ME, Achenbach SJ, Huddleston JM, Therneau TM, Leibson CL. Secular trends in hip fracture incidence and recurrence. Osteoporosis international. 2009 May 1;20(5):687-94.

3. David GL. Fractures of hip, In Canale S Terry, (ed), campbells operative Orthopedics 10th edition, Mosby Year Book; St. Louis, London. 1998; 3:2873-2938.

4. Kyle RF. Fracture of the proximal part of the femur. Journal of Bone and Joint Surgery (Br); 1994; 76-A:924-948. 
5. Kannus P, Parkkari J, Sievänen H, Heinonen A, Vuori I, Järvinen M. Epidemiology of hip fractures. Bone. 1996 Jan 1;18(1):S57-63.

6. Pajarinen J, Lindahl J, Michelsson O, Savolainen V, Hirvensalo E. Pertrochanteric femoral fractures treated with a dynamic hip screw or a proximal femoral nail: a randomised study comparing postoperative rehabilitation. The Journal of bone and joint surgery. British volume. 2005 Jan;87(1):7681.

7. Al-Yassari G, Langstaff RJ, Jones JW, Al-Lami M. The AO/ASIF proximal femoral nail (PFN) for the treatment of unstable trochanteric femoral fracture. Injury. 2002 Jun 1;33(5):395-9.

8. Ecker ML, Joyce 3rd JJ, Kohl EJ. The treatment of trochanteric hip fractures using a compression screw. The Journal of bone and joint surgery. American volume. 1975 Jan 1;57(1):23-7.

9. Parker MJ, Pryor GA. The timing of surgery for proximal femoral fractures. The Journal of bone and joint surgery. British volume. 1992 Mar;74(2):203-5.

10. Simmermacher RK, Bosch AM, Van der Werken $\mathrm{CH}$. The AO/ASIF-proximal femoral nail (PFN): a new device for the treatment of unstable proximal femoral fractures. Injury. 1999 Jun 1;30(5):32732.

11. Domingo L, Cecilia D, Herrera A, Resines C. Trochanteric fractures treated with a proximal femoral nail. International orthopaedics. 2001 Oct 1;25(5):298-301.

12. Herrera A, Domingo L, Calvo A, Martinez A, Cuenca J. A comparative study of trochanteric fractures treated with the Gamma nail or the proximal femoral nail. International orthopaedics. 2002 Dec 1;26(6):365-9.

13. Banan H, Al-Sabti A, Jimulia T, Hart AJ. The treatment of unstable, extracapsular hip fractures with the AO/ASIF proximal femoral nail (PFN) our first 60 cases. Injury. 2002 Jun 1;33(5):401-5.

14. Boldin C, Seibert FJ, Fankhauser F, Peicha G, Grechenig W, Szyszkowitz R. The proximal femoral nail (PFN)-a minimal invasive treatment of unstable proximal femoral fractures: a prospective study of 55 patients with a follow-up of 15 months. Acta Orthopaedica Scandinavica. 2003 Jan 1;74(1):53-8. 